\title{
A Retrospective Study of Nephrectomy Done At Bpkihs
}

\author{
Shah $\mathrm{RS}^{1}$, Agrawal CS \\ ${ }^{1,2}$ Department Of Urology
}

\begin{abstract}
Purpose: To know the epidemiological profile, frequency and indications of different types of nephrectomy performed at BPKIHS, a retrospective study.

Materials and Methods: There were a total of 63 patients who underwent Nephrectomy at BPKIHS from 2068 B.S to 2072 B.S The file of patients that was collected from the authorities from hospital record section was used to obtain necessary data for research purpose. All the details from files of every patient were collected and were filled up in predesigned proforma. All the information provided was kept confidential and was assessed and the personal information was not shared to anyone outside. Data was entered in Microsoft Excel 2007 and converted into SPSS (statistical package for social science) 11.5 version for statistical analysis.

Results: In this study, majority of patients belong to age group of 25 to 50 years. The mean age of patients is $44.3( \pm 15.8 \mathrm{SD})$ years ranging from 9 years to 73 years. Most of them presented with complaints of abdominal pain ( $81 \%)$ followed by fever (12.7\%). Gender and real angle tenderness were significantly correlated. Left side Kidney (52.4\%) was found to be a bit more involved. Ultrasonography was found to be more effective in diagnosing the Non-functioning Kidney due to complications secondary to chronic obstruction to undergo Nephrectomy. USG was also able to diagnose 5 out of 7 cases of malignancy that underwent Radical Nephrectomy. Majority of the cases were diagnosed to be Non-Functioning Kidney due to Chronic Obstructive Nephropathy(84.1\%) followed by malignancies(11.1\%).In all the Nephrectomies performed, all the malignant conditions were operated through radical nephrectomy(11.1\%) and simple nephrectomy was done in(88.9\%).

Conclusions: This study suggests the need of dire urgency to provide better health services at basic level and increase in awareness by education to decrease the rate of nephrectomy for preventable conditions, like renal stone disease. All nephrectomy specimens should be subjected to histopathological examination. Open simple nephrectomy, which remains our common practice, is safe and unilateral nephrectomy is compatible with normal life.
\end{abstract}

\section{Introduction}

Nephrectomy is a surgical procedure for theremoval of kidney on patients with severe kidneydamage from disease, injury, or congenital conditions. These include cancer of the kidney (renalcell carcinoma); polycystic kidney disease (a diseasein which cysts, or sac-like structures, displace healthykidney tissue); and serious kidney infections. It is alsoused to remove a healthy kidney from a donor for thepurposes of kidney transplantation.Nephrectomy is of many types: simple, partial and radical nephrectomy. (Abdulkareem et al, 2015)

In simple nephrectomy the kidney is dissected free through the convenient plane between the capsule and its fatty coverings. (Fowler, 2013)

In partial nephrectomy, only the diseased or infected portion of the kidney is removed. Radical nephrectomy involves removing the entire kidney, the ureter, the adrenal gland, and the fatty tissue surrounding the kidney. In a traditional, open nephrectomy, the kidney donor is administered general anesthesia and a 6-10 in $(15.2-25.4 \mathrm{~cm})$ incision through several layers of muscle is made on the side or front of the abdomen. The blood vessels connecting the kidney to the donor are cut and clamped, and the ureter is also cut between the bladder and kidney and clamped. (Cameron, 1999)

Nephrectomy may involve removing a small portion of the kidney or the entire organ and surrounding tissues. In partial nephrectomy, only the diseased or infected portion of the kidney is removed. Radical nephrectomy involves removing the entire kidney, a section of the tube leading to the bladder, the gland that sits atop the kidney, and the fatty tissue surrounding the kidney. A simple nephrectomy performed for living donor transplant purposes requires removal of the kidney and a section of the attached ureter.('Nephrectomy', Encyclopedia, 2004)

There are geographical variations in indications for nephrectomy as certain urological diseases are moreprevalent in some countries.(Andualem et al, 2012)

Nephrectomy is one of the common urological surgeries done at BPKIHS. In the last six months, 12 nephrectomies have been done here. In most of the patients, renal calculi were the most common cause. In developing countries like Nepal, patients may not be aware that stone disease can also lead to non-functioning kidney which may finally land upto nephrectomy. So we have planned this study to know the frequency, causes 
of nephrectomy and epidemiological profile of the patients so that we can plan awareness programmes for the community to receive early treatment or consult nearby doctor in case of pain abdomen. Also, there hasn't been any similar study done on nephrectomy in our country to the best of our literature search.

i. To know the epidemiological profile of patients.

\section{Aims \& Objectives}

ii. To know the frequency of different types of nephrectomy performed.

iii. To know about the indications of different nephrectomy.

- Research Method: Quantitative

\section{Design and methodology}

- $\quad$ Study Design: Retrospective Study

- $\quad$ Sampling Methods/Techniques: Simple random sampling

- Data Collection Technique / Methods:The files of patients that was collected from the authorities from hospital record section was used to obtain necessary data for research purpose. All the details from files of every patient were collected and were filled up in predesigned pro forma. All the information provided was kept confidential and was assessed and the personal information was not shared to anyone outside

- Data Collection Tools: Patients' detail Files

- Whether study involves Human/animals or both: Human

- Population/ participants: There were a total of 63 patients who underwent Nephrectomy at BPKIHS from 2068 B.Sto 2072 B.S

- Human study: Yes

- Inclusion Criteria: Patients who underwent Nephrectomy at BPKIHS from 2068 B.Sto 2072 B.S

- Exclusion Criteria: Patients whose documents were not available

- Primary (main outcome):Indications of Nephrectomy

- Rational for statistical methods to be employed: Attached

- Ethical clearance: Ethical clearance will be obtained as per the institutional guidelines from IRC.

- Whether available resources are adequate: Yes

- Other resources needed: Not needed

- Permission from Drug Controller of Nepal: Not needed.

- Safety measure: NA

- Plan to withdraw: NA

\section{Data entry and Analysis:}

Data was entered in Microsoft Excel 2007 and converted into SPSS (statistical package for social science) 11.5 versions for statistical analysis. For descriptive statistics, percentage, mean and Standard deviation were calculated along with graphical and tabular presentation.

\section{Results}

In our present study we found that majority of the patients belong to age group of 25 to 50 years as shown in figure 1. The mean age of patients is 44.3 ( $\pm 15.8 \mathrm{SD})$ years ranging from 9 years to 73 years. The median age found was 46 years.

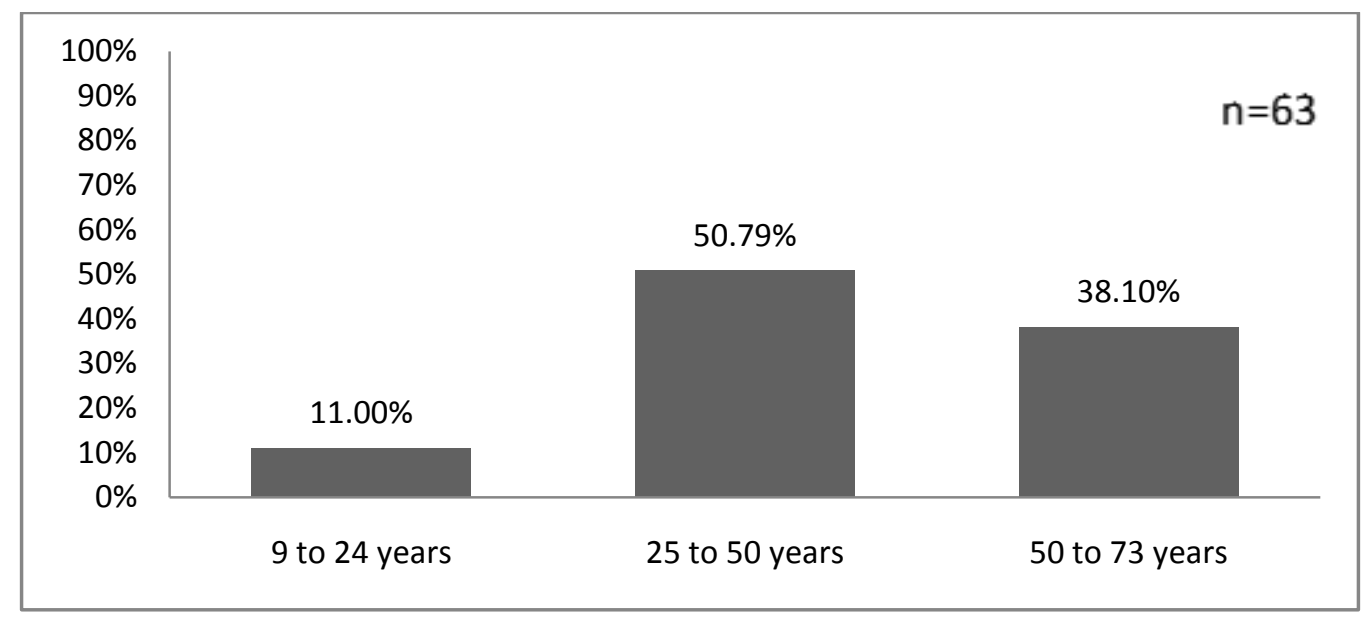


Figure 1.Age Group of patients who underwent nephrectomy

Among patients, we found that $50.8 \%$ of the patients were female and $49.2 \%$ of them were male.

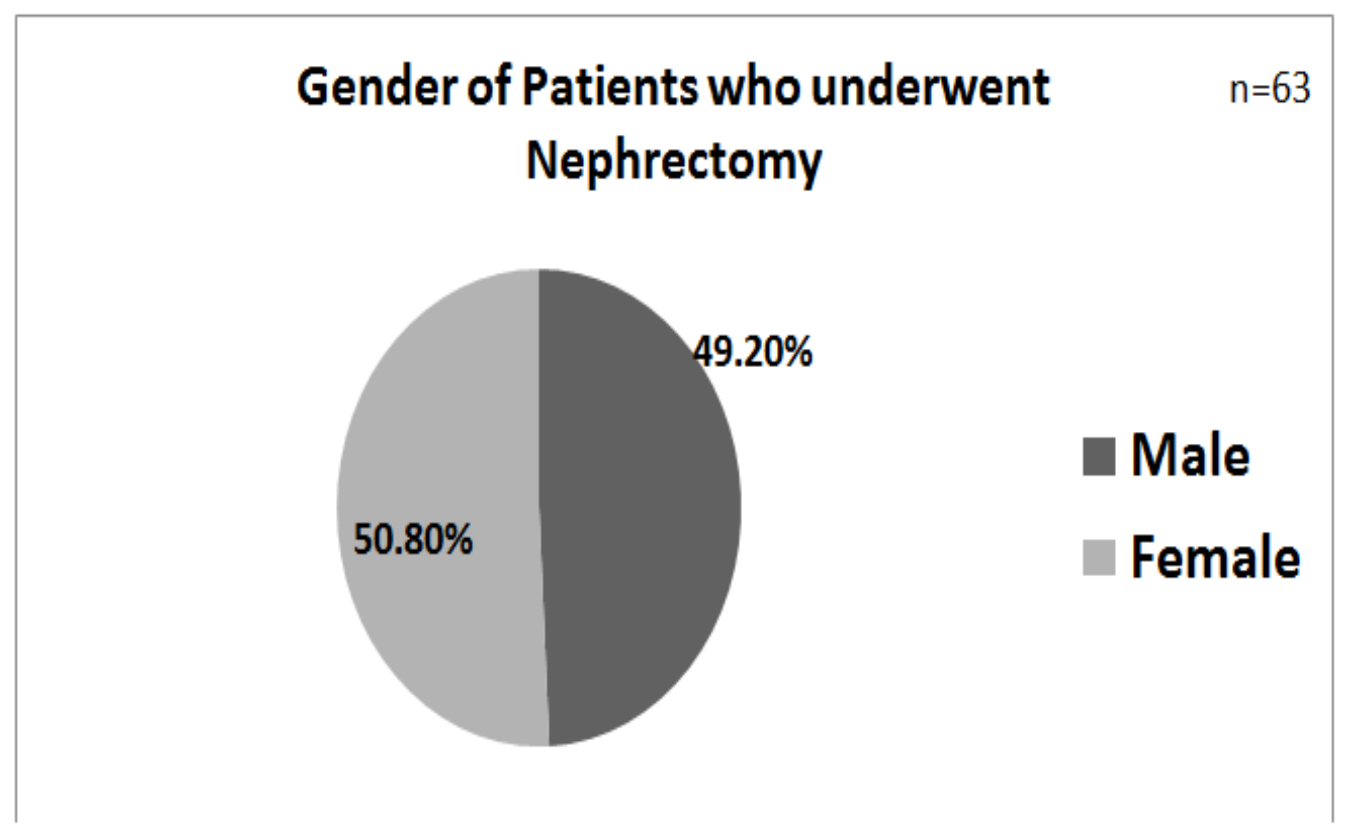

Figure 2 Gender distribution of patients

Majority of the patients (81\%) presented to BPKIHS with the complaints of abdominal pain followed by fever and $22.2 \%$ of the patients had a history of any surgical intervention done in the past. $11.1 \%$ of the patients were also found to have renal angle tenderness on examination.

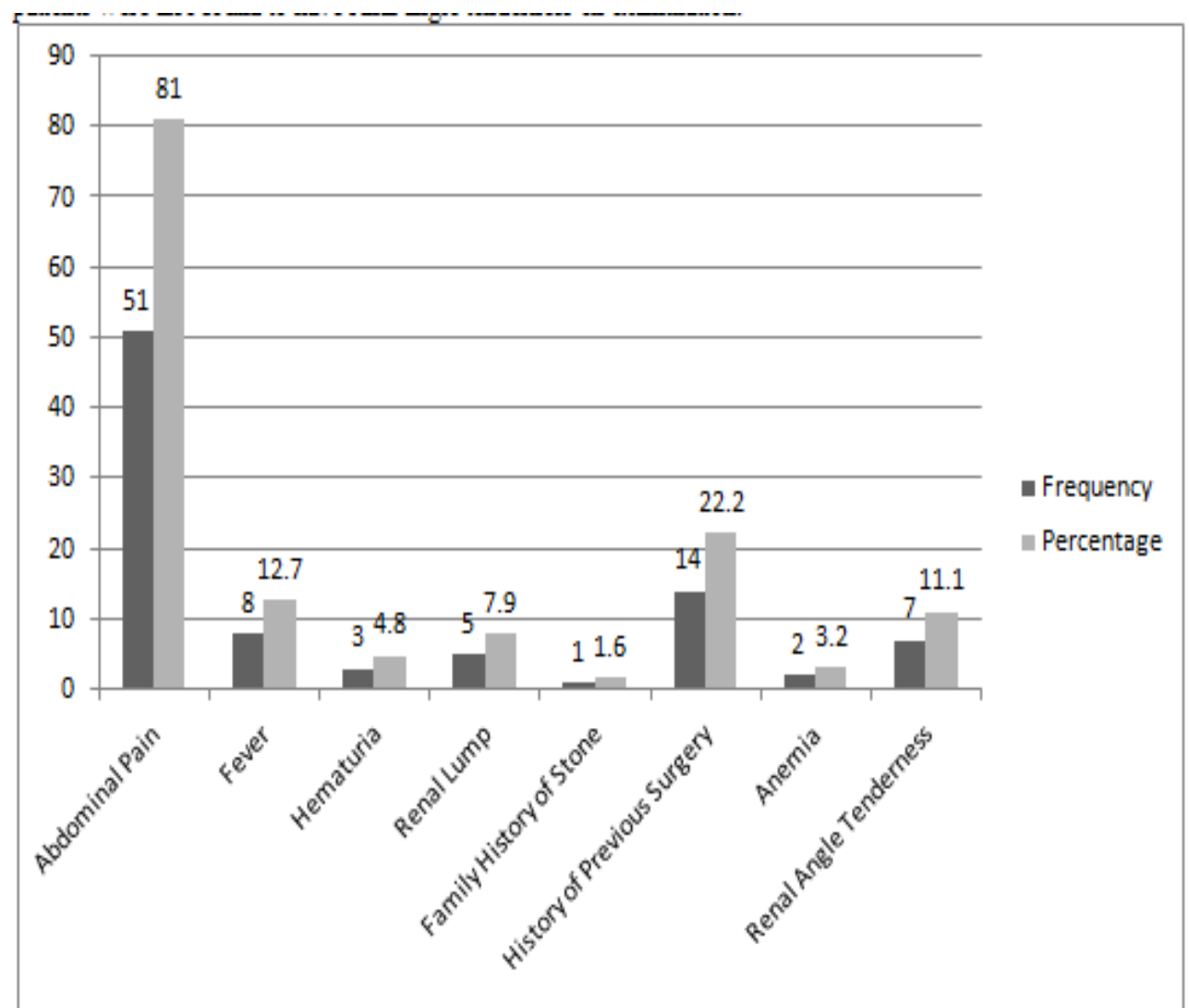

Fig 3.Bar Graph showing the history and examination findings of the patients *more than one symptom was presented by patients 
Among those patients $(n=63)$ included in this study, history of renal angle tenderness was present in 7 patients and absent in 56 patients. Further all the patients who had history of renal angle tenderness were female. As such there seems to be a significant correlation $(\mathrm{p}<0.05)$ between renal angle tenderness and gender of patients.

Table 1.Table showing the cross tabulation in sex and renal angle tenderness.

\begin{tabular}{|c|c|c|c|}
\hline \multirow{2}{*}{ Sex } & \multicolumn{2}{|c|}{ Renal Angle Tenderness } & \multirow{2}{*}{ Total } \\
\hline & Present & Absent & \\
\hline Male & $\mathbf{0}$ & 31 & 31 \\
\hline Female & 7 & 25 & 32 \\
\hline Total & 7 & 56 & 63 \\
\hline
\end{tabular}

Out of $31.7 \%$ of patients who had comorbid conditions, the incidence of comorbidities ranked as follows:

Hypertension $(80 \%)$

Diabetes Mellitus (5\%)

Pulmonary Tuberculosis(5\%)

Valvular Heart Disease (5\%)

Hypertension with Diabetes Mellitus(5\%)

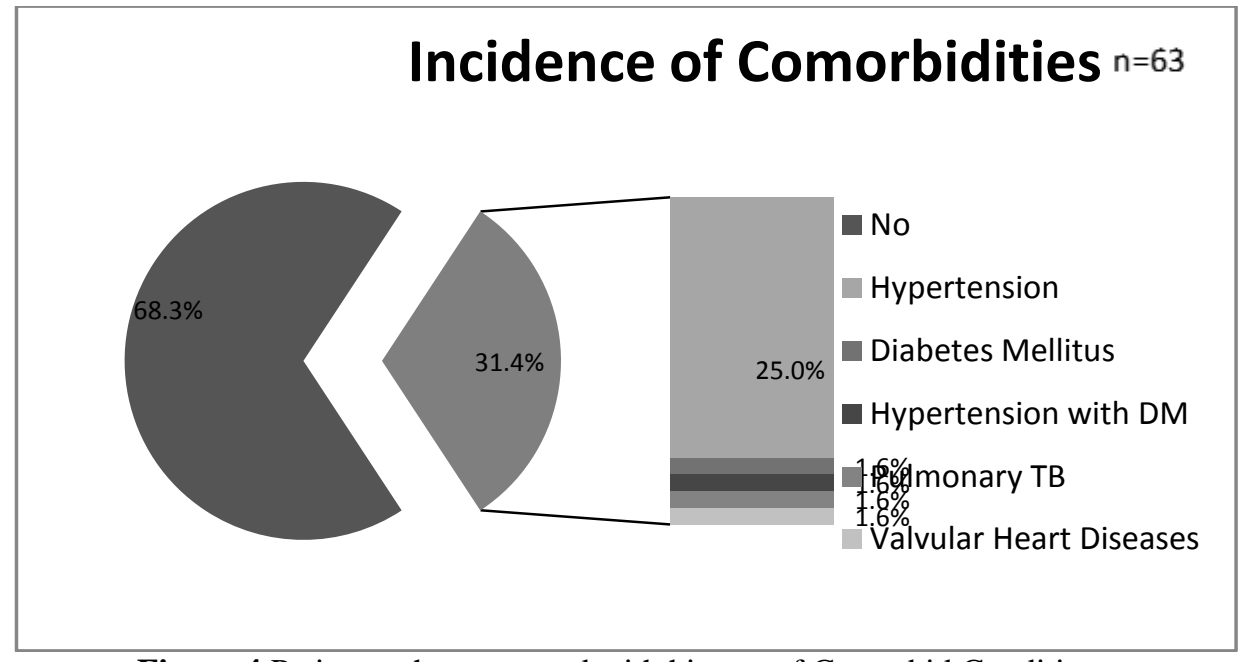

Figure 4.Patients who presented with history of Comorbid Conditions

$11.1 \%$ of the total patients had exposure to the risk factors.Out of those who were exposed to the risk factors, $28.57 \%$ were smokers whereas $71.43 \%$ had exposure to both smoking and alcohol consumption.

On urine culture, most of them $(87.3 \%$ ) were sterile while $7.90 \%$ showed Escherichiacoli growth and only $4.8 \%$ showed growth of Klebsiella species. Further data on sensitivity could not be obtained.

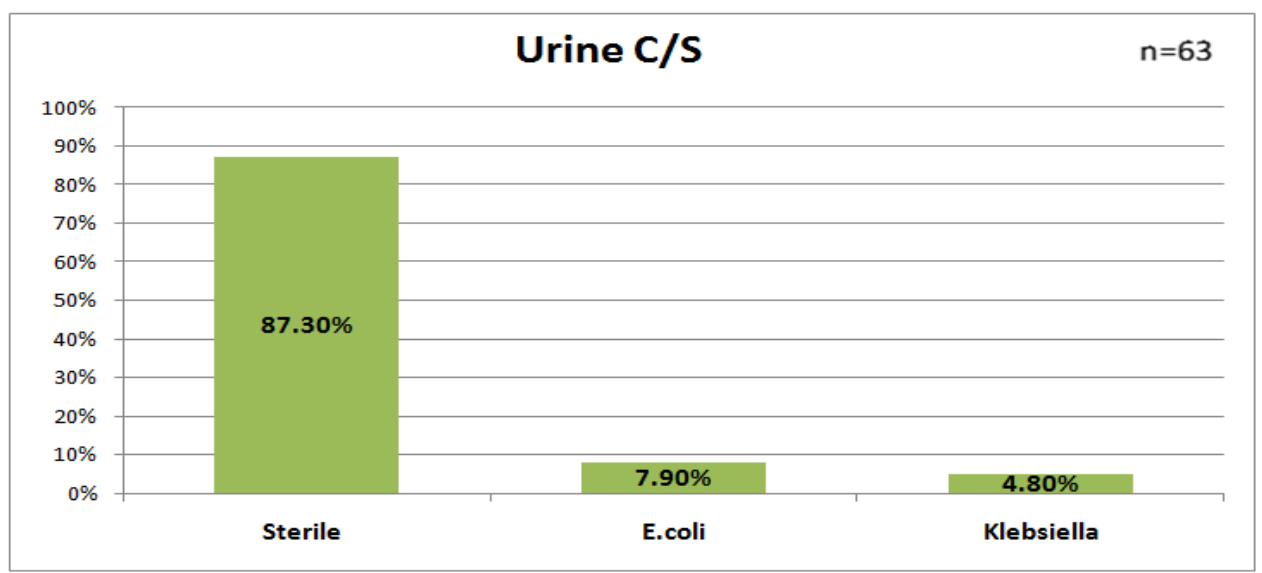

Figure 5.Urine Culture results in the patients. 
On laboratory investigation parameters, $4.8 \%$ and $6.4 \%$ of the total patients had deranged blood serum level values of urea and creatinine respectively while $22.2 \%$ and only $1.6 \%$ of the patients had altered sodium and potassium levels in their blood respectively as shown in table 2 .

Table 2.Investigation results of blood serum level of various components

\begin{tabular}{|c|c|c|c|c|}
\hline Blood serum level & $\begin{array}{l}\mathrm{Na} \\
(135-145 \mathrm{mmol} / \mathrm{dL})\end{array}$ & $\begin{array}{l}\mathrm{K} \\
(3.6-5.0 \mathrm{mmol} / \mathrm{dL})\end{array}$ & $\begin{array}{l}\text { Urea } \\
(15-40 \mathrm{mg} / \mathrm{dL})\end{array}$ & $\begin{array}{l}\text { Creatinine } \\
(0.7-1.4 \mathrm{mg} / \mathrm{dL})\end{array}$ \\
\hline Normal & $69.8 \%$ & $90.5 \%$ & $95.2 \%$ & $93.6 \%$ \\
\hline High & $11.1 \%$ & $1.6 \%$ & $3.2 \%$ & $3.2 \%$ \\
\hline Low & $11.1 \%$ & - & $1.6 \%$ & $3.2 \%$ \\
\hline Not Available & $7.9 \%$ & $7.9 \%$ & - & - \\
\hline
\end{tabular}

Our study showed a slight dominance in the involvement of left kidneys rather than right in being diseased.

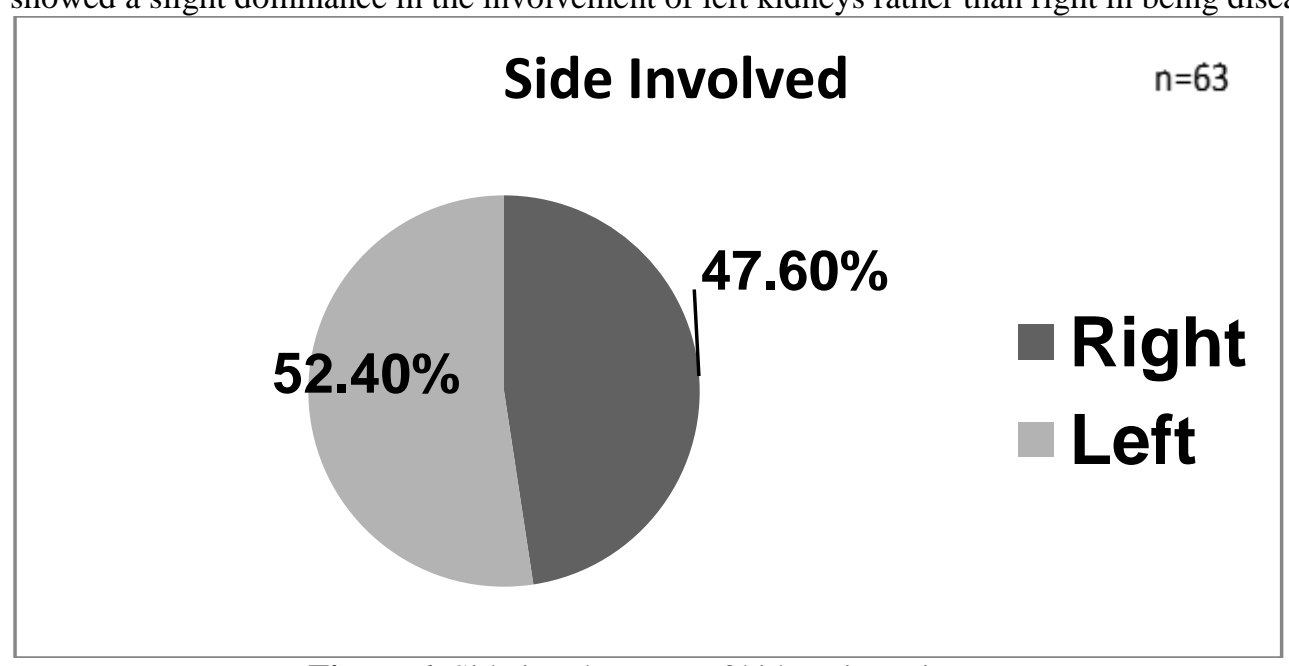

Figure 6. Side involvement of kidney in patients

In a total of 45 patients who underwent ultrasonography, majority of them showed grossly hydronephrotic kidney and non-functioning kidney due to single or multiple calculi as shown in Table 3.

Table 3.Ultrasonography findings of the patients

\begin{tabular}{|l|l|l|}
\hline Ultrasonography Findings & Frequency & Percentage \\
\hline Grossly Hydronephrotic kidney & $\mathbf{2 4}$ & $\mathbf{5 3 . 3 3}$ \\
\hline Non functioning kidney due to single or multiple caculi & $\mathbf{1 0}$ & $\mathbf{2 2 . 2 2}$ \\
\hline Kidney or Upper Urinary Tract Cancer & 5 & 11.11 \\
\hline Cystic Lesion & 3 & 6.67 \\
\hline Pyonephrosis & 3 & 6.67 \\
\hline Others & 1 & 2.22 \\
\hline Total & $\mathrm{N}=45$ & 100 \\
\hline
\end{tabular}

A total of 38 patients underwent Intravenous Urography and it showed majority of problems in the kidney rather than the urinary tract as shown in Table 4. 
Table 4. Intra Venous Urography Findings of the patients

\begin{tabular}{|l|l|l|}
\hline Intra Venous Urography Findings & Frequency & Percentage \\
\hline Non Excreting Kidney & $\mathbf{3 4}$ & $\mathbf{8 9 . 4 7}$ \\
\hline PUJ Obstruction & 2 & 5.26 \\
\hline Non Excreting Kidney with PUJ obstruction & 2 & 5.26 \\
\hline Total & $\mathrm{N}=38$ & 100 \\
\hline
\end{tabular}

In the 15 patients who underwent CT Urography, they mainly had calculi and soft tissue density lesion as shown in Table 5.

Table 5. CT Urography Findings of the patients

\begin{tabular}{|l|l|l|}
\hline CT Urography Findings & Frequency & Percentage \\
\hline Calculi & $\mathbf{4}$ & $\mathbf{2 6 . 6 7}$ \\
\hline Soft tissue density lesion & $\mathbf{4}$ & $\mathbf{2 6 . 6 7}$ \\
\hline PUJ obstruction & 2 & 13.33 \\
\hline Enlarged kidney & 2 & 13.33 \\
\hline Enlarged kidney with PUJ obstruction & 1 & 6.67 \\
\hline Renal Cyst & 1 & 6.67 \\
\hline Others & 1 & 6.67 \\
\hline Total & $\mathrm{N}=15$ & 100 \\
\hline
\end{tabular}

Also in a total of 28 patients for DTPA scan, poor functioning kidney was shown in 21 of them and 4 refused to do the scan as shown in Figure 9.

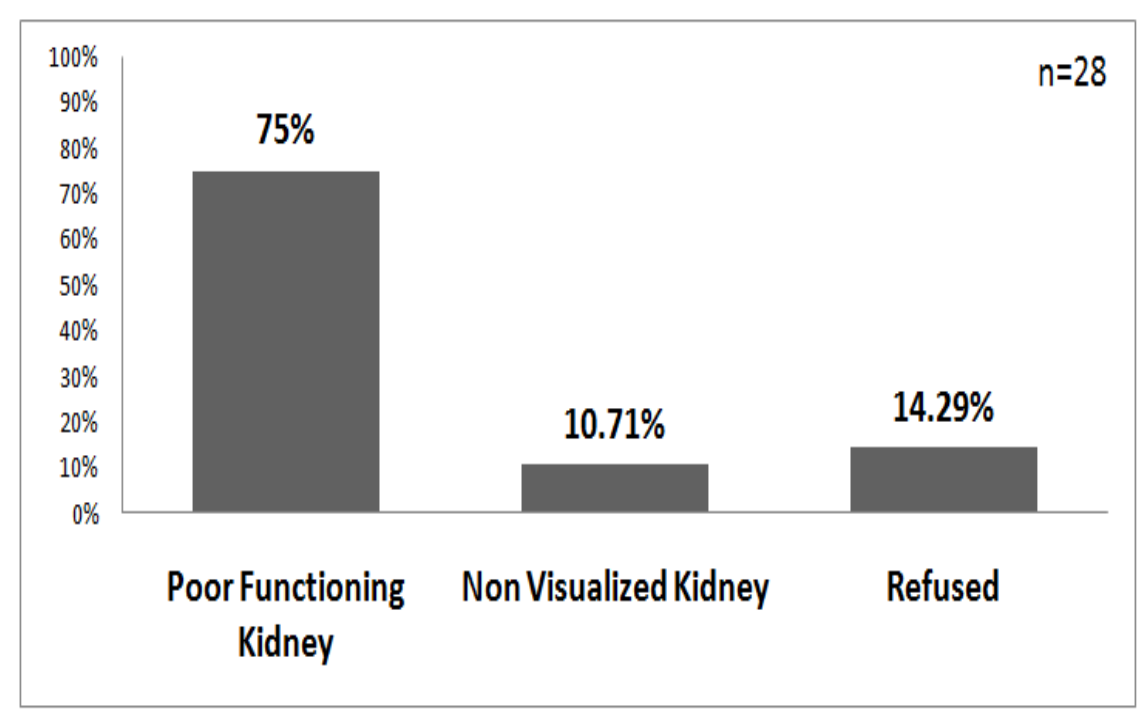

Figure 7. DTPA Scan Findings of the patients

Majority of the cases were diagnosed to be Non-Functioning Kidney due to Chronic Obstructive Nephropathy followed by malignancies as shown in Table 6 . 
Table 6.Final Diagnosis in the patients

\begin{tabular}{|l|l|l|}
\hline Final Diagnosis & Frequency & Percentage \\
\hline Non Functioning Kidney due to complication secondary to obstruction & $\mathbf{5 3}$ & $\mathbf{8 4 . 1}$ \\
\hline Renal Cell Carcinoma(RCC) & $\mathbf{6}$ & $\mathbf{9 . 5}$ \\
\hline Transitional Cell Carcinoma(TCC) & 1 & 1.6 \\
\hline Renal Cyst & 2 & 3.2 \\
\hline Atrophied Kidney & 1 & 1.6 \\
\hline Total & N=63 & 100 \\
\hline & & \\
\hline
\end{tabular}

In all the surgeries done, all malignant conditions were operated through radical nephrectomy and simple nephrectomy was done in $88.9 \%$ of the cases as shown in Fig 8 .

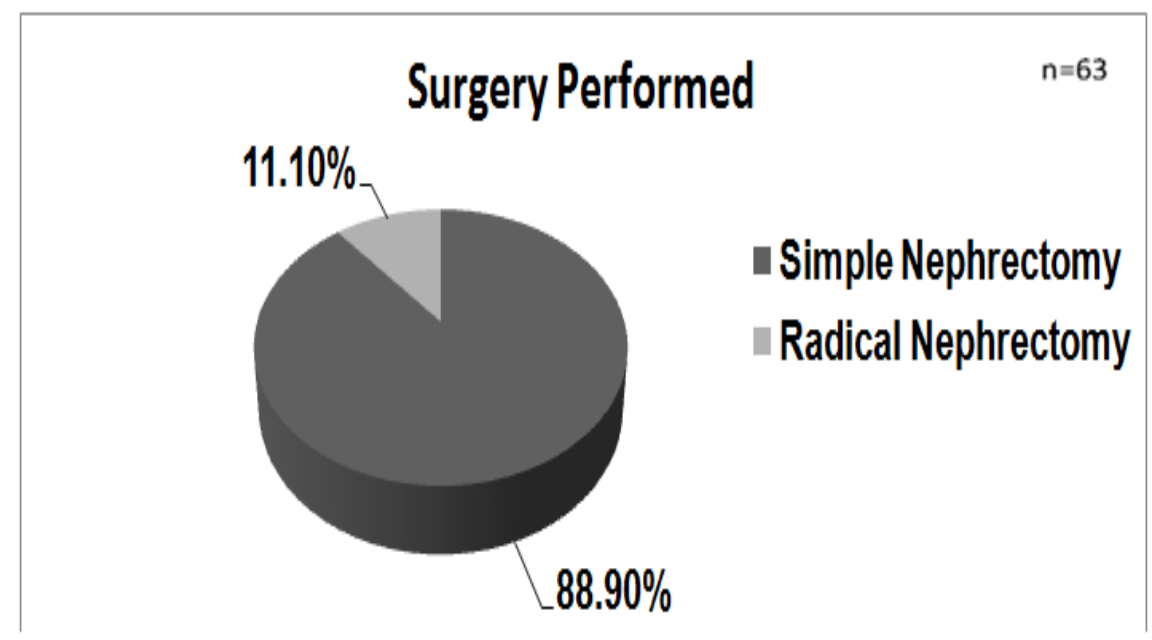

Fig 8.Pie chart showing type of nephrectomy performed.

Among those patients $(\mathrm{N}=63)$ included in our study, 7 cases were found to be malignant conditions and other 56 were benign conditions. Simple nephrectomy was done in 56 patients whereas radical nephrectomy was performed in 7 of them. Further, 7 cases that were found to be malignant were all operated through radical nephrectomy as shown in table 7 . On analysing the data, we found that there is a significant correlation $(\mathrm{p}<$ $0.05)$ between surgery performed and the type of lesion in kidney.

Table 7. Table showing cross tabulation between type of lesion and surgery performed.

\begin{tabular}{|c|c|c|c|}
\hline \multirow{2}{*}{ Type } & \multicolumn{2}{|c|}{ Surgery Performed } & \multirow{2}{*}{ Total } \\
\hline & Simple Nephrectomy & Radical Nephrectomy & \\
\hline Benign Conditions & 56 & $\mathbf{0}$ & 56 \\
\hline Malignant Conditions & $\mathbf{0}$ & 7 & 7 \\
\hline Total & 56 & 9 & $n=63$ \\
\hline
\end{tabular}

\section{Discussion}

The kidney like other organs is liable to different diseases vary from congenital diseases, inflammatory and neoplastic lesion. In our study, in 63 cases, majority of the patients belonged to the age group 25-50 years with mean age of 44.3 years similar to a study done by EIFadilet al.

In the present study, among nephrectomy specimens, $50.8 \%$ were of females and $49.2 \%$ of males, with $\mathrm{M}: \mathrm{F}=1: 1.03$. This ratio is inconcordance with the $\mathrm{M}: \mathrm{F}$ ratio of 1:1.05 observed by Rafique , Aiman and Abdulkareem et al.However, El Fadil et al reported $61 \%$ nephrectomy specimens in males and $39 \%$ in females with $\mathrm{M}: \mathrm{F}=1.9: 1$. 
We found that there is significant correlation between gender of the patient and renal angle tenderness in our study but we couldn't find any such literature with such finding.

In their clinical assessment, most of them presented with chief complains of abdominal pain $(81 \%)$ which is also in consistent with studies by El Fadil et al and Popat et al.

From the literature that we have reviewed there is definitely a geographic variation regarding the indications for nephrectomy. The indications of nephrectomy in developing countries like India, Pakistan, Jordan, Saudi Arabia and Sudan are mainly for benign conditions like non-functioning kidney due to stone or obstruction which is consistent to our study also. Rafiquein his publication from Pakistan reported outcome of 154 nephrectomy from 2001 to 2005 that showed $76.6 \%$ nephrectomy being performed for benign conditions with the mean age at presentation of 32 years. Datta et al published analysis of 88 nephrectomy in a rural tertiary centre of India that showed $62.5 \%$ of nephrectomy was for benign conditions. In most of the reported series, from developing countries, benign diseases of the kidney were the leading causes of nephrectomy.

Malignancy is the second most common indication in our region by our study which has been seen as more common indication of nephrectomy in developed countries.

In our present study, a total of $7(11.1 \%)$ malignant lesions were observed; of these, renal cell carcinomas seen in 6 cases $(85.7 \%)$. This was similar to the findings of Rafiquewho observed that the majority of malignant neoplasms (97\%) of the kidney were renal cell carcinomas. Popat et al in their study, found that $70 \%$ of malignant lesions were accounted for by renal cell carcinomas. Of the 6 cases of Renal Cell Carcinoma, only $16.67 \%$ were males and $83.33 \%$ were females which is incomparable to study bySidharth et al and Abdulkareem et al where male:female ratio were higher.

Ultrasonography has long been hailed for its superiority in the diagnosis of hydronephrosis. In this study, it proved its value in the diagnosis of chronic obstruction. Out of 45 USGs done, 40 were diagnosed as case of chronic obstruction by this procedure which is consistent to study done by Andualem et al, 2012.

\section{Limitations}

As this study is a retrospective study, we had to limit our findings as per the record files only. Many fields on our predesigned pro-forma had to be left blank. We had a very limited amount of time to accomplish our study, otherwise a larger number of samples could have been covered by our study.

\section{Conclusion}

In this study, majority of patients belong to age group of 25 to 50 years. The mean age of patients is 44.3 ( $\pm 15.8 \mathrm{SD})$ years ranging from 9 years to 73 years.Most of them presented with complaints of abdominal pain $(81 \%)$ followed by fever $(12.7 \%)$. Gender and real angle tenderness were significantly correlated. Left side Kidney $(52.4 \%)$ was found to be a bit more involved.

Ultrasonography was found to be more effective in diagnosing the Non-functioning Kidney due to complications secondary to chronic obstruction to undergo Nephrectomy.USG was also able to diagnose 5 out of 7 cases of malignancy that underwent Radical Nephrectomy.

Majority of the cases were diagnosed to be Non-Functioning Kidney due to Chronic Obstructive Nephropathy $(84.1 \%)$ followed by malignancies(11.1\%).In all the Nephrectomies performed, all the malignant conditions were operated through radical nephrectomy(11.1\%) and simple nephrectomy was done in $(88.9 \%)$.

\section{Suggestions And Recommendations}

This study suggests the need of dire urgency to provide better health services at basic level and increase in awareness by education to decrease the rate of nephrectomy for preventable conditions, like renal stone disease.All nephrectomy specimens should be subjected to histopathological examination. Open simple nephrectomy, which remains our common practice is safe and unilateral nephrectomy is compatible with normal life.

\section{Follow Up}

Research paper dealt with a unique operative procedure on which no any such study has been done in our country as per our literature search. We chose this topic precisely because of the fact that a common disease condition like stone disease may land upto nephrectomy. Our research concern basically divided the whole paper into two distinct sections. The first and primary concern was what are the causes leading to nephrectomy in the patients. The second concern was the frequency of the nephrectomy performed and the demographic profile of the patients.

To answer our concerns, we went through the record files of every patients who underwent nephrectomy in BPKIHS from 2068 B.S. to 2072 B.S. We extracted the medical records through their admission reports, operation reports and discharge report to meet our purpose. We kept the record according to pre- 
designed pro-forma to keep data of their demographic profile, complaints, examination findings, investigative findings, diagnosis and operation performed.

The most obvious thing we would do differently if we had the chance to do this paper again would be to stay on schedule and finish the paper on time. I feel that writing a paper over a short period of time was a tedious task to accomplish. Due to time constraints and the broadness of the topic we had to opt for a retrospective study module. We feel that a prospective study module would have more accurately depicted and answered the concerns that the topic dealt with. We also had to go through the files many times to rectify errors that crept in. We also believe that completing the paper on time would have given us time to do some extra projects.

During the writing process we had quite a few ideas with possible topics for further study. One thing we have in mind is the study on the quality of life of patients who underwent nephrectomy. Further study on postoperative conditions and complications of the procedure on the patients who underwent nephrectomy can also be done. Similar studies can be done in other health institutions of the country so that we would have a better overall understanding of the disease processes and the requirement of this operative procedure in our country.

\section{Refrences}

[1]. Abdulkareem, A.S., B. Hassawi and Z. Ahmed, 'Nephrectomy, A clinicopathological study', Journal of American Science, vol. 11, no. 8, 2015, pp. 97-101.

[2]. Aiman, A., K. Singh and M. Yasir, 'Histopathological spectrum of lesions in nephrectomy specimens: A five-year experience in a tertiary care hospital', J SciSoc, vol. 40, 2013, pp. 148-54

[3]. Andualem, D., B. Teklebrihan and C. Wuletaw, 'Indications, Complications and Mortality of Nephrectomy in TikurAnbesa General Specialized Hospital', East and Central African Journal of Surgery, vol. 17, no. 3, 2012, pp. 92-7

[4]. Cameron, J. S. Kidney Failure: The Facts. New York, Oxford University Press, 1999

[5]. Datta, B. et al., 'Analysis of 88 nephrectomies in a rural tertiary care center of India', Saudi J Kidney Dis Transpl, vol. 23, 2012, pp. 409-13

[6]. Davenport, K. et al., 'A 3-year review of The British Association of Urological Surgeons Section of Endourology Laparoscopic Nephrectomy Audit', British Association of Urological Surgeons, vol. 97, no. 2, 2006, pp. 333-7

[7]. El Fadil, M.A.E.M. etal., 'Nephrectomy in Adults: Asir Hospital Experience',Saudi Journal of Kidney Diseases and transplantation, vol. 8, 1997, pp. 423-427.

[8]. Fowler,C., 'The kidneys and ureters', in Bailey and Love's short practice of surgery, 26 ${ }^{\text {th }}$ edition, Boca Raton, CRC Press, 2013, pp. $1282-308$

[9]. Gupta, D.K. et al., 'Nephron Sparing Surgery in a Tertiary Care Center in Nepal- An Initial Experience', J Nepal Health Res Counc, vol. 12 , no. 27,2014 , pp. $109-11$

[10]. 'Nephrectomy', Gale Encyclopedia of Surgery: A Guide for Patients and Caregivers 2004 http://www.encyclopedia.com/topic/Nephrectomy.aspx, (accessed 11 July 2016)

[11]. Popat, V.C. et al., 'A study on culprit factors ultimately demanding nephrectomy', Internet J Urol, vol. 7, no. 1, 2010, p. 1

[12]. Rafique, M. et al., 'Nephrectomy: Indications, complications and mortality in 154 consecutive patients', J Pak Med Assoc, vol. 57, 2007, pp. 308-11.

[13]. Sidharth et al., 'Pattern of Renal Cell Carcinoma - A Single Center Experience in Nepal', Kathmandu University Medical Journal, vol.9, no. 35, 2011, pp.185-8

[14]. Stephen, R. et al., 'The British Association of Urological Surgeons Section of Endourology audit of laparoscopic nephrectomy', British Association of Urological Surgeons, vol. 94, no. 4, 2004, pp 577-81.

[15]. Walsh, P.C. et al. 'Surgery of the kidney', in Campbell's Urology, $8^{\text {th }}$ edition, Philadelphia. USA, 2002, pp. 3570-3643 